\title{
Decreased Prolidase Activity in Patients with Posttraumatic Stress Disorder
}

\author{
Süleyman Demir ${ }^{1} \bowtie$, Mahmut Bulut ${ }^{1}$, Abdullah Atli ${ }^{1}$, İbrahim Kaplan², Mehmet Cemal Kaya ${ }^{1}$, \\ Yasin Bez ${ }^{3}$, Pınar Güzel Özdemir ${ }^{4}$, and Aytekin Sır ${ }^{1}$ \\ 1Department of Psychiatry, Dicle University, Diyarbakir, Turkey \\ ${ }^{2}$ Department of Biochemistry, Dicle University, Diyarbakir, Turkey \\ ${ }^{3}$ Department of Psychiatry, Marmara University, Istanbul, Turkey \\ ${ }^{4}$ Department of Psychiatry, Van Yüzüncü Yıl University, Van, Turkey
}

Objective Many neurochemical systems have been implicated in the development of Posttraumatic Stress Disorder (PTSD). The prolidase enzyme is a cytosolic exopeptidase that detaches proline or hydroxyproline from the carboxyl terminal position of dipeptides. Prolidase has important biological effects, and to date, its role in the etiology of PTSD has not been studied. In the present study, we aimed to evaluate prolidase activity in patients with PTSD.

Methods The study group consisted of patients who were diagnosed with PTSD after the earthquake that occurred in the province of Van in Turkey in $2011(\mathrm{n}=25)$; the first control group consisted of patients who experienced the earthquake but did not show PTSD symptoms $(n=26)$ and the second control group consisted of patients who have never been exposed to a traumatic event ( $n=25)$. Prolidase activities in the patients and the control groups were determined by the ELISA method using commercial kits.

Results Prolidase activity in the patient group was significantly lower when compared to the control groups. Prolidase activity was also significantly lower in the traumatized healthy subjects compared to the other healthy group $(\mathrm{p}<0.01)$.

Conclusion The findings of the present study suggest that the decrease in prolidase activity may have neuroprotective effects in patients with PTSD.

Psychiatry Investig 2016;13(4):420-426

Key Words PTSD, Prolidase activity, Neuroprotective.

\section{INTRODUCTION}

Posttraumatic stress disorder (PTSD) is a mental health problem that results after hearing about, witnessing, or experiencing a traumatic event. ${ }^{1}$ The recurring flashbacks, avoidance and numbing, and hyper-arousal are the common symptoms of PTSD. Interestingly, traumatizing events can vary and often include incidents such as car accidents, rape, war, or natural disasters all of which may threaten the life of individuals. ${ }^{2-4}$ In addition, PTSD is frequently encountered after earthquakes. ${ }^{5,6}$ In population-based studies performed

Received: May 19, 2015 Revised: September 6, 2015

Accepted: September 17, 2015 Available online: February 17, 2016

$\triangle$ Correspondence: Süleyman Demir, MD

Department of Psychiatry, Dicle University, Diyarbakir 21280, Turkey

Tel: +90 (506) 4972567, Fax: +90 (412) 2488523

E-mail: drsuleymandemir@hotmail.com

(a) This is an Open Access article distributed under the terms of the Creative Commons Attribution Non-Commercial License (http://creativecommons.org/licenses/bync/3.0) which permits unrestricted non-commercial use, distribution, and reproduction in any medium, provided the original work is properly cited. after earthquakes, the rate of PTSD was reported to vary between $3.0 \%$ and $87.0 \% .^{7-9}$

The number of neurobiological studies on PTSD has increased in recent years. More than one neurochemical system has been suggested to be involved in PTSD. For example, adrenergic, dopaminergic, serotonergic, GABAergic, glutamatergic, and neuro-endocrinological systems are involved in the stress response of the organism when an individual is exposed to a traumatic event. Several reports have indicated that trauma causes short or long-standing structural and functional changes in the central nervous system. ${ }^{10-13}$

The prolidase enzyme is a cytosolic exopeptidase that detaches proline or hydroxyproline from the carboxyl terminal position of dipeptides, and it is found in plasma and in various organs such as the brain, heart, uterus, and thymus. ${ }^{14,15}$ Prolidase is associated with the metabolism of many biological molecules. Additionally, it has important roles in the physiological and pathological processes, including embryonic development, remodeling of the extracellular matrix, wound 
healing, inflammation, carcinogenesis, angiogenesis, cell migration, and cell differentiation. ${ }^{16-19}$

Proline is important in the brain and is regarded as a neurotransmitter. The increases in prolidase levels are associated with higher proline levels. The prolidase enzyme in the brain is important for proline metabolism. ${ }^{20}$ The deficiency of the prolidase enzyme causes an autosomal recessive disease characterized by mental retardation, recurring infections, splenomegaly, and skin lesions. ${ }^{21}$ As in many disorders, prolidase activity has also been evaluated in patients with mental disorders. ${ }^{22-25}$ Jacquet et al. concluded that hyperprolinemia may be a risk factor for schizoaffective disorder. ${ }^{26}$ In addition, Selek et al. reported higher prolidase activity in patients with bipolar disorder. ${ }^{20}$

Prolidase enzyme, which possesses important biological effects, has not been studied for its role in the etiology of PTSD. In the present study, we aimed to evaluate prolidase activity in patients that developed PTSD after an earthquake.

\section{METHODS}

\section{Patient and control groups}

The study group consisted of patients that made up three groups. The first group (group 1) who were diagnosed with PTSD after an earthquake that occurred in the province of Van in Turkey in 2011; the second control group (group 2) consisted of patients who experienced the earthquake but did not exhibit PTSD symptoms; and the third control group (group 3) consisted of patients who have never been exposed to a traumatic event. The present study included subjects between 18 and 65 years of age. Group 1 and group 2 consisted of subjects who experienced the earthquakes that occurred in October 23, 2011 and November 9, 2011 in the province of Van in Turkey. Group 3 consisted of subjects who were living in the province of Diyarbakır in Turkey and who did not have a history of trauma. The subjects in the control and patient groups had similar sociodemographic characteristics. Twenty five patients was choosed as group 1 suitable for study criteria, among 43 patients with PTSD diagnosis admitted to pscyhiatry clinic before treatment. Group 2 consists of 26 patients suitable for study criteria among 61 healthy individuals applied the blood bank for donation who experienced the earthquake. Group 3 consists of 25 healthy individuals, suitable for study criteria, among 56 individuals who applied the blood bank for donation. Groups 1 and 2 were taken into study 6 months after the earthquake.

The subjects who were diagnosed with a comorbid psychiatric axis I or II disorder according to DSM-IV TR were not included in group 1. Pregnant women, vitamin and fish-oil users, and cases with severe systemic disease, epileptic seizures, diabetes mellitus, hypertension, substance and alcohol addicts, and those with severe head trauma or mental retardation were also not included in the study.

The participants signed a voluntary informed consent form, and this was followed by the administration of sociodemographic information forms and study scales. Blood samples were collected for biochemical analyses. After obtaining administrative permission of Dicle University, the study was approved by the local ethics committee.

\section{Data forms}

\section{Sociodemographic information form}

This form was prepared by the researchers, and it contains questions about age, educational level, gender, marital status, BMI, and smoking habits.

\section{PTSD Checklist-Civilian Version}

PTSD Checklist-Civilian Version (PCL-C) was developed by Weathers et $\mathrm{al}^{27}$ and the validity and reliability of the Turkish version of this scale was evaluated by Kocabaşoğlu et al..$^{28}$ Using this scale, the presence of PTSD symptoms in the last onemonth can be evaluated in subjects who experience a traumatic event. The PCL-C was a self-reported measure and contained a total of 17 items, consisting of three symptom clusters. Of these items, seven were related to avoidance, five were related to hyper-arousal, and five were related to recurring flashback symptoms. The items were rated on a 6-point scale from 0 (not at all) to 5 (extremely). A total score of 50 or more was diagnostic for PTSD. $^{29}$

\section{Clinical Global Impression Scale}

Clinical Global Impression Scale (CGI) is a three-dimensional scale, and it is administered during a semi-structured interview conducted by the physician in order to determine the therapeutic responses of the patients with psychiatric disorders. This scale was developed by Guy to evaluate the course of all psychiatric disorders. In this study, the severity of the disease was evaluated using the Clinical Global ImpressionSeverity of Illness (CGI-SI) scale. The subjects with a psychiatric disorder were graded from 1 and 7: 1=normal, not at all ill, 2=borderline mentally ill, 3=mildly ill, 4=moderately ill, $5=$ markedly ill, $6=$ severely ill, and $7=$ extremely ill. ${ }^{30}$

PCL-C was administered to group 1 and group 2 . The scales were not administered to group 3 due to the absence of a trauma history.

\section{Collection of blood samples and measurement of prolidase activity}

Venous blood samples were collected at 8:00 AM after a 12- 
hour fasting period. Blood samples were centrifuged at 3,000 rpm for 10 minutes, and the sera were separated. The sera were stored at $-80^{\circ} \mathrm{C}$ until the analysis. Serum samples were liquefied on the day of analysis and prolidase activities were determined. Prolidase activities were measured by an ELISA method using commercial kits in laboratories of the Department of Biochemistry at Dicle University Medical Faculty.

\section{Statistical analysis}

The statistical analysis of the data was conducted using SPSS

Table 1. Gender, marital status, smoking status, age, educational level, and BMI evaluations in the groups

\begin{tabular}{|c|c|c|c|}
\hline & \multicolumn{3}{|c|}{ Gender } \\
\hline & Female, N (\%) & Male, N (\%) & $\chi^{2} / \mathrm{p}$ \\
\hline Group 1 & $15(60)$ & $10(40)$ & \\
\hline Gorup 2 & $15(57.7)$ & $11(42.3)$ & 0.038 \\
\hline Group 3 & $15(60)$ & $10(40)$ & 0.981 \\
\hline \multirow[t]{3}{*}{ Total } & $45(59.2)$ & $31(40.8)$ & \\
\hline & \multicolumn{3}{|c|}{ Marital status } \\
\hline & Married, N (\%) & Single, N (\%) & \\
\hline Group 1 & $17(68)$ & $8(32)$ & \\
\hline Gorup 2 & $19(76)$ & $7(24)$ & 2.457 \\
\hline Group 3 & $17(68)$ & $8(32)$ & 0.652 \\
\hline \multirow[t]{3}{*}{ Total } & $53(69.7)$ & $23(30.3)$ & \\
\hline & \multicolumn{3}{|c|}{ Smoking status } \\
\hline & Smoker, N (\%) & Non-smoker, N (\%) & \\
\hline Group 1 & $8(32)$ & $17(68)$ & \\
\hline Gorup 2 & $14(53.8)$ & $12(46.2)$ & 5.255 \\
\hline Group 3 & $6(24)$ & $19(76)$ & 0.072 \\
\hline \multirow[t]{2}{*}{ Total } & $28(36.8)$ & $48(63.2)$ & \\
\hline & $\mathrm{N}$ & Mean \pm SD & $\mathrm{F} / \mathrm{p}$ \\
\hline \multicolumn{4}{|l|}{ Age } \\
\hline Group 1 & 25 & $33.72 \pm 13.126$ & \\
\hline Gorup 2 & 26 & $30.58 \pm 6.626$ & 0.798 \\
\hline Group 3 & 25 & $30.20 \pm 11.394$ & 0.454 \\
\hline \multicolumn{4}{|l|}{ Education } \\
\hline Group 1 & 25 & $11.60 \pm 3.279$ & \\
\hline Gorup 2 & 26 & $11.35 \pm 3.322$ & 0.840 \\
\hline Group 3 & 25 & $12.32 \pm 1.069$ & 0.436 \\
\hline \multicolumn{4}{|l|}{ BMI } \\
\hline Group 1 & 25 & $23.5509 \pm 3.24$ & \\
\hline Gorup 2 & 26 & $22.8766 \pm 2.83$ & 0.715 \\
\hline Group 3 & 25 & $23.8368 \pm 2.42$ & 0.493 \\
\hline
\end{tabular}

Group 1: Patient Group, Group 2: Individuals experienced the earthquake but did not exhibit PTSD symptoms Group, Group 3: Healty Group. $\mathrm{p}<0.05$ : statistically Significant. BMI: body mass index, PTSD: post traumatic stress disorder
15.0. The chi-square test was used to compare frequencies and ratios of the categorical variables. The continuous variables were expressed as mean $\pm \mathrm{SD}$. The means of continuous variables in three groups were compared using the ANOVA test. The parameters that were found to be significant in the ANOVA test were evaluated in paired groups using Post Hoc Tamhane test. The Student's t-test was used to compare the mean values of continuous variables between the two groups. The Pearson's correlation coefficient was used to evaluate the correlations. A p-value less than 0.05 ( $\mathrm{p}<0.05)$ was considered statistically significant.

\section{RESULTS}

Gender, marital status, smoking status, age, educational level, and BMI did not differ significantly between the groups. Gender, marital status, smoking status, age, educational level, and $\mathrm{BMI}$ in the patient and control groups are presented in Table 1.

Prolidase activity were evaluated in the patient and control groups. Prolidase activity showed a statistically significant difference between the groups. Prolidase activity in the patient

Table 2. Prolidase activity evaluations in the groups

\begin{tabular}{ccrc}
\hline & $\mathrm{N}$ & $\mathrm{Mean} \pm \mathrm{SD}$ & $\mathrm{F} / \mathrm{p}$ \\
\hline Prolidase & & & \\
Group 1 & 25 & $417.87 \pm 685.61$ & \\
Group 2 & 26 & $812.96 \pm 328.78$ & 14.344 \\
Group 3 & 25 & $1283.24 \pm 584.53$ & $<0.001$ \\
\hline
\end{tabular}

Group 1: patient group, Group 2: individuals experienced the earthquake but did not exhibit PTSD symptoms group, Group 3: healty group. $\mathrm{p}<0.05$ : statistically significant

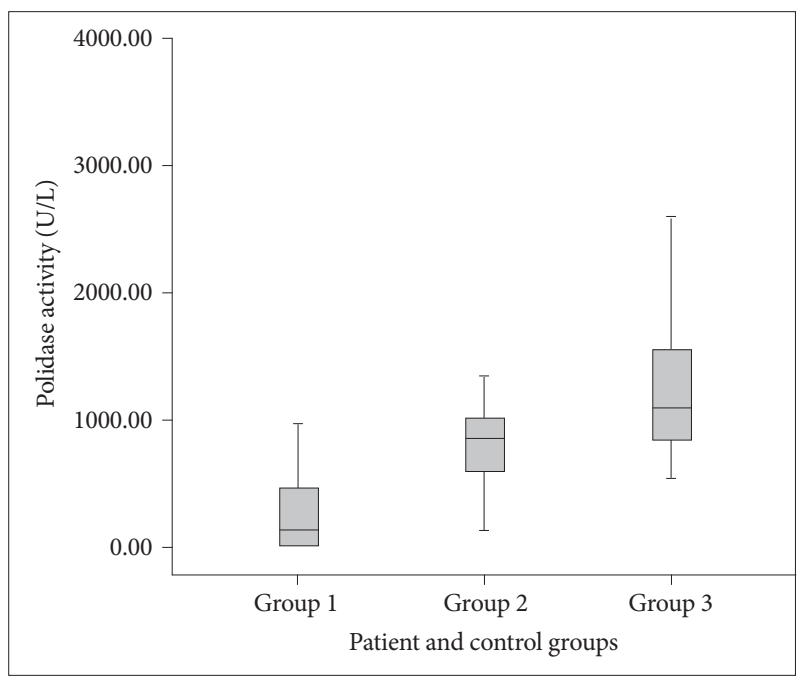

Figure 1. Prolidase activities in the patient and control groups. Group 1: patient group, Group 2: individuals experienced the earthquake but did not exhibit PTSD symptoms group, Group 3: healthy group. PTSD: post traumatic stress disorder. 
and control groups are presented in Table 2.

Prolidase activity showed statistically significant differences between the groups when evaluated by ANOVA test $(\mathrm{F}=$ $14.344, \mathrm{p}=0.001$ ). The groups were compared as pairs using the post-hoc Tamhane test. Prolidase activity showed statistically significant differences between the patient and control groups, and also between the two control groups $[\mathrm{p}=0.045$ (group 1-2); $\mathrm{p}<0.001$ (group 1-3); and $\mathrm{p}=0.006$ (group 2-3), respectively]. Prolidase activities in the patient and control groups are illustrated in Figure 1.

PCL-C and CGI scores in group 1 were 48.80 \pm 16.31 and $4.00 \pm 0.61$, respectively. In group 2, PCL-C scores was $23.35 \pm$ 5.34. The differences in PCL-C scores between the groups were found to be statistically significant $(t=7.549 \mathrm{p}<0.001)$.

The correlations between the prolidase activity and age, educational level, and BMI were evaluated in the patient and control groups. There was no correlation between the prolidase activity and age, educational level, or BMI in the patient and control groups ( $\mathrm{p}>0.05)$.

The correlations between the prolidase activity, and PCL$\mathrm{C}$ and CGI scores in group 1 were evaluated. No correlation was found between the prolidase activity and PCL-C or CGI scores in group 1 ( $p>0.05)$. The correlations between the prolidase activity, and PCL-C scores in group 2 were evaluated. No correlation was found between the prolidase activity and PCL-C scores in group 2 ( $\mathrm{p}>0.05)$.

The correlation between the prolidase activity and smoking status was also evaluated. Prolidase activity did not differ significantly between smokers and non-smokers in the patient and control groups ( $\mathrm{p}>0.05)$.

\section{DISCUSSION}

The present study is the first to evaluate prolidase activity in patients with PTSD. The most important finding of the present study is the significantly low prolidase activity in the Patient Group when compared to the control groups. In addition, prolidase activity was found to be significantly lower in individuals experienced the earthquake but did not exhibit PTSD symptoms groupcompared to healthy group.

The studies have reported a decrease in prefrontal cortex activity and the observation of structural changes in hippocampus in patients with PTSD. ${ }^{31,32}$ The studies have also reported an increased production of free radicals as a stress response in the hippocampus, and increased oxidative stress was suggested to mediate hippocampal damage. ${ }^{33,34}$ Nitric oxide (NO) is an oxidative molecule, and has been suggested to exert its excitatory effects on the central nervous system by activating guanylate cyclase in the presynaptic terminal. Hence, causing the release of glutamate via cGMP and increased glutamate
NMDA receptor activation in the postsynaptic membrane. ${ }^{35-37}$

An excessive glutamate release in the hippocampus and prefrontal cortex during traumatic events causes oxidative stress and excitotoxicity. The activation of NO, glutamate, and NMDA receptors have major roles in stress-related hippocampal degeneration. ${ }^{12,38-40}$ It was suggested that sustained NO release in PTSD might be related to neural degeneration. In addition, hippocampal atrophy and cognitive deficits associated with PTSD have been related to increased release of $\mathrm{NO}$ and glutamate and hyperactivation of NMDA receptors. ${ }^{41-45}$ NMDA and Nitric Oxide Synthase (NOS) antagonists were shown to be effective in the treatment of PTSD. Furthermore, antidepressants used in the treatment of PTSD were suggested to decrease glutamate level and inhibit NOS. ${ }^{43,46-51}$

Proline, a non-essential amino acid, is synthesized from glutamate by the reversal of reactions in proline catabolism. ${ }^{52}$ Endogenous extracellular proline is considered to increase the effects of glutamate in the synaptic cleft. ${ }^{53}$ Increased proline levels were shown to activate NMDA receptors. ${ }^{53-56}$ Prolidase has an important role in the regulation of NO biosynthesis. NO, which is involved in many biological processes, and prolidase are considered to have a strong relation with each other. ${ }^{57-59} \mathrm{NO}$ is shown to increase in cells in repairement process released by macrophage cells that are activated as part of the immune response. ${ }^{59,60}$ It is shown that NO plays an important role in collagen metabolism. ${ }^{59}$ Because of the fact that approximately $\% 25$ of the amino acids in the collagen tissue consist of proline and hydroxyproline, prolidase plays an important role in collagen metabolism. ${ }^{61}$ It was shown that Nitric Oxide regulates prolidase activity with phosporylation of prolidase enzyme through cGMP kinase. ${ }^{59}$

Glutamate and NO levels are elevated in PTSD and have been documented for their neurotoxic effects. ${ }^{45}$ The decreased prolidase activity in PTSD may cause a decrease in NO and glutamate levels. This notion has been supported by the regulatory role of prolidase in the synthesis of NO. Proline is excreted in the urine when prolidase activity decreases. ${ }^{62}$ Proline is synthesized from glutamate. ${ }^{52}$ The decrease in proline level can be restored from glutamate, and this can also decrease glutamate levels. In addition, decreased proline levels can lead to a decrease in glutamatergic activity in the synaptic cleft and inhibition of NMDA receptors. These mechanisms have led to our suggestion that decreased prolidase activity might produce a neuroprotective effect that prevents neurotoxic effects of $\mathrm{NO}$ and glutamate.

Lower prolidase activity in individuals experienced the earthquake but did not exhibit PTSD symptoms group when compared to healthy group (and lower prolidase level in patients when compared to individuals experienced the earthquake but did not exhibit PTSD symptoms group) also lead 
to the consideration that prolidase plays a compensatory role in the neurotoxicity increased by stress.

Increasing prolidase activity was shown to be related with oxidative-stress in bipolar disorder. ${ }^{20}$ However it does not seem possible to establish a relationship between prolidase activity that decreases in PTSD and oxidative-stress due to the fact that oxidative-stress levels in PTSD are generally similar to that of healthy individuals. ${ }^{63,64}$ However it was found that NO levels are increased in bipolar disorder like in PTSD. ${ }^{65,66}$ It is found that prolidase activity is increased in schizophrenia patients according to healthy controls. ${ }^{67}$ It was suggested that Glutamatergic/NMDA receptor dysfunction could play a role in the potential pathogenesis of the schizophrenia patient. ${ }^{68,69}$ Just as increasing prolidase activity in schizophrenia and bipolar disorder may cause NO, glutamate and NMDA receptors' dysfunction, resulting in being associated with neurodegeneration, decreasing prolidase activity in PTSD could thus be associated with neuroprotective effect.

No difference was found between the patient and control groups in terms of gender, age, educational level, BMI, and smoking status. While creating the study groups, subjects in the patient and control groups were selected from individuals that had similar sociodemographic characteristics. The present study showed in whom trauma could influence prolidase activity independent from other factors.

In previous studies, prolidase activity was found to be related with oxidative stress and NO which is an oxygen radicale. The relationship between these parameters and the prolidase activity has been evaluated since oxidative stress can be affected by age, gender, smoking and body mass index (BMI) ${ }^{20,22,24,25,59}$ In the patient and control groups, no correlation was found between prolidase activity and age, gender, BMI, smoking status. A study by Yildız et al. evaluated prolidase activity in patients with coronary artery disease and found no relation between smoking status and prolidase activity. This finding supports and is consistent with our current results. ${ }^{70}$ We put forth the notion that neural damage associated with smoking may be related to the number of cigarettes smoked, duration of smoking, and age smoking onset. The above-mentioned factors were not investigated in detail in the present study. Therefore, it is not possible to draw conclusions about the effects of smoking on prolidase activity.

Limitations of this study include low patient numbers of study groups and non-evaluation of $\mathrm{NO}$ and glutamate levels along with prolidase activities, single measurement of prolidase activity and non-evaluation of post-treatment prolidase activity.

We suggest that the decrease in prolidase activity in PTSD could result in a neuroprotective effect. However, repetitive measurements where NO and glutamate levels are evaluated along with prolidase activity is necessary in order to have a clear identification of the neuroprotective effect of decrease in prolidase activity in PTSD with wider patient series.Molecules that affect prolidase activity must be considered when determining treatment options for PTSD.

\section{REFERENCES}

1. American Psychiatric Association. Diagnostic and Statistical Manual of Mental Disorders, 5th Edition. Washington, DC: American Psychiatric Association; 2013.

2. Smith MY, Redd WH, Peyser C, Vogl D. Posttraumatic stress disorder in cancer: a review. Psychooncology 1999;8:521-537.

3. Tedstone JE, Tarrier N. Posttraumatic stress disorder following medical illness and treatment: a review. Clin Psychol Rev 2003;23:409-448.

4. Pine DS, McClure EB. Clinical Features of Anxiety Disorders. In: Sadock BJ, Sadock VA, Editors. Kaplan \& Sadocks's Synopsis of Psychiatry: Behavioral Sciences, Clinical Psychiatry. 9th edition. Philadelphia: Lippincott Williams \& Wilkins Publishing, 2003, p. 623-631.

5. Briere J, Elliott D. Prevalence, characteristics, and long-term sequelae of natural disaster exposure in the general population. J Trauma Stress 2000;13:661-679.

6. Kokai M, Senta F, Naotaka S, Edwards G. Natural disaster and mental health in Asia. Psychiatry Clin Neurosci 2004;58:110-116.

7. Başoğlu M, Şalcıoğlu E, Livanou M. Traumatic stress responses in earthquake survivors in Turkey. J Trauma Stress 2002;15:269-276.

8. Lai TJ, Chang CM, Connor KM, Lee LC, Davidson JR. Full and partial PTSD among earthquake survivors in rural. J Psychiatr Res 2004;38:313322.

9. Aker AT. 1999 Marmara Earthquakes: a review of epidemiologic findings and community mental health policies. Turk Psikiyatri Derg 2006;17:204-212.

10. Bremner JD. Does stress damage the brain? Biol Psychiatry 1999;45:797805.

11. Villarreal G, Petropoulos H, Hamilton DA, Rowland LM, Horan WP, Griego JA, et al. Proton magnetic resonance spectroscopy of the hippocampus and occipital white matter in PTSD: preliminary results. Can J Psychiatry 2002;47:666-670.

12. Harvey BH, Oosthuizen F, Brand L, Wegener G, Stein DJ. Stress-restress evokes sustained iNOS activity and altered GABA levels and NMDA receptors inrat hippocampus. Psychopharmacology (Berl) 2004;175:494502.

13. Su YA, Wu J, Zhang L, Zhang Q, Su DM, He P, et al. Dysregulated mitochondrial genes and networks with drug targets in postmortem brain ofpatients with posttraumatic stress disorder (PTSD) revealed by human mitochondria-focusedcDNA microarrays. Int J Biol Sci 2008;4:223-235.

14. Zanaboni G, Dyne KM, Rossi A, Monafo V, Cetta G. Prolidase deficiency: biochemical study of erythrocyte and skin fibroblast prolidase activity in Italian patients. Haematologica 1994;79:13-18.

15. Vural M, Camuzcuoglu H, Toy H, Aksoy N. Amniotic fluid prolidase activity and oxidative status in neural tube defects. Fetal Diagn Ther 2010;28:34-39.

16. Palka JA, Phang JM. Prolidase activity in fibroblasts is regulated by interaction of extracellular matrix with cell surface integrin receptors. J Cell Biochem 1997;67:166-175.

17. Berrier AL, Yamada KM. Cell-matrix adhesion. J Cell Physiol 2007; 213:565-573.

18. Hu CA, Phang JM, Valle D. Proline metabolism in health and disease. Preface. Amino Acids 2008;35:651-652.

19. McRae PA, Porter BE. The perineuronal net component of the extracellular matrix in plasticity and epilepsy. Neurochem Int 2012;61:963-972.

20. Selek S, Altindag A, Saracoglu G, Celik H, Aksoy N. Prolidase activity and its diagnostic performance in bipolar disorder. J Affect Disord 2011; 129:84-86.

21. Mandel H, Abeling N, Gutman A, Berant M, Scholten EG, Sheiman C, 
et al. Prolidase deficiency among an Israeli population: prenatal diagnosis in a genetic disorder with uncertain prognosis. Prenat Diagn 2000;20: 927-929.

22. Aslan M, Nazligul Y, Horoz M, Bolukbas C, Bolukbas FF, Aksoy N, et al. Serum prolidase activity and oxidative status in Helicobacter pylori infection. Clin Biochem 2007;40:37-40.

23. Andreazza AC, Kauer-Santanna M, Frey BN, Bond DJ, Kapczinski F, Young LT, et al. Oxidative stress markers in bipolar disorder: a metaanalysis. J Affect Disord 2008;111:135-144.

24. Cakmak A, Zeyrek D, Atas A, Celik H, Aksoy N, Erel O. Serum prolidase activity and oxidative status in patients with bronchial asthma. J Clin Lab Anal 2009;23:132-138.

25. Cakmak A, Soker M, Koc A, Aksoy N. Prolidase activity and oxidative status in patients with thalassemia major. J Clin Lab Anal 2010;24:6-11

26. Jacquet H, Demily C, Houy E, Hecketsweiler B, Bou J, Raux G, et al. Hyperprolinemia is a risk factor for schizoaffective disorder. Mol Psychiatry 2004;10:479-485.

27. Weathers FW, Litz BT, Herman DS, Jusca J, Keane TM. The PTSD Checklist: Reliability, Validity and Diagnostic Utility. San Antonio, TX: Paper presented at the annual meeting of the International Society for Traumatic Stress Studies; 1993.

28. Kocabaşoğlu N, Çorapcıoğlu ÖA, Yargıc Ï, Geyran P. The validity and safety of turkish "PTSD checkust - civilian version" (PCL-C) scale. New Symposium 2005;43:126-134.

29. Kocabaşoğlu N, Özdemir S. An overwiev of the rating scales used in posttraumatic stress disorder. New Symposium 2005;43:173-178.

30. Guy W. ECDEU Assessment Manual for Psychopharmacology. Revised US Dept Health, Education and Welfare publication (ADM). Rockville, MD: National Institude of Mental Health; 1976.

31. Knox D, Perrine SA, George SA, Galloway MP, Liberzon I. Single prolonged stress decreases glutamate, glutamine, and creatine concentrations in the ratmedial prefrontal cortex. Neurosci Lett 2010;480:16-20.

32. Kitayama N, Vaccarino V, Kutner M, Weiss P, Bremner JD. Magnetic resonance imaging (MRI) measurement of hippocampal volume in posttraumatic stress disorder: a metaanalysis. J Affect Disord 2005;88:79-86.

33. Fontella FU, Siqueira IR, Vasconcellos AP, Tabajara AS, Netto CA, Dalmaz C. Repeated restraint stress induces oxidative damage in rat hippocampus. Neurochem Res 2005;30:105-111.

34. Burgess N. Spatial cognition and the brain. Ann NY Acad Sci 2008;1124: 77-97.

35. Yildiz F, Ulak G, Erdeb BF, Gacar N. Anxolytic-like effects of 7-nitroindazole in the rat plus-maze test. Pharmacol Biochem Behav 2000;65: 199-202.

36. Uzbay T. Neurobiology of anxiety and depression. Clin Psychiatry 2004; (suppl 4):3-11.

37. dos Reis EA, de Oliveira LS, Lamers ML, Netto CA, Wyse AT. Arginine administration inhibits hippokampal $\mathrm{Na}(+), \mathrm{K}(+)$-ATPase activity and impairs retention of an inhibitory avoidance task in rats. Brain Res 2002; 951:151-157.

38. Almeida A, Heales SJR, Bolanos JP, Medina JM. Glutamate neurotoxicity is associated with nitric oxide-mediated mitochondrial dysfunction and glutathione depletion. Brain Res 1998;790:209-216.

39. Vermetten E, Bremner JD. Circuits and systems in stress: applications to neurobiology and treatment in posttraumatic stress disorder. Depress Anxiety 2002;16:14-38.

40. Colas D, Gharib A, Bezin L, Morales A, Guidon G, Cespuglio R, et al. Regional age-related changes in nöronal nitric oxide synthase (nNOS), messenger RNA levels and activity in SAMP8 brain. BMC Neurosci 2006;7:81.

41. Chambers RA, Bremner JD, Moghaddam B, Southwick SM, Charney DS, Krystal JH. Glutamate and post-traumatic stress disorder: towards a psychobiology of dissociation. Semin Clin Neuropsychiatry 1999;4:274281.

42. Elzinga BM, Bremner JD. Are the neural substrates of memory the final common pathway in posttraumatic stress disorder (PTSD)? J Affect Dis- ord 2002;70:1-17.

43. Heresco-Levy U, Kremer I, Javitt DC, Goichman R, Reshef A, Blanaru $\mathrm{M}$, et al. Pilot-controlled trial of D-cycloserine for the treatment of posttraumatic stress disorder. Int J Neuropsychopharmacol 2002;5:301-307.

44. Harvey BH, Bothma T, Nel A, Wegener G, Stein DJ. Involvement of the NMDA receptor, NO-Cyclic GMP and nuclear factor K-beta in an animal model of repeated trauma. Hum Psychopharmacol 2005;20:367-373.

45. Oosthuizen F, Wegener G, Harvey BH. Nitric oxide as inflammatory mediator in post-traumatic stress disorder (PTSD): evidence from an animal model. Neuropsychiatr Dis Treat 2005;1:109-123.

46. Padovan CM, Del Bel EA, Guimaraes FS. Behavioral effects in the elevated plus maze of an NMDA antagonist injected into the dorsal hippocampus: influence of restraint stress. Pharmacol Biochem Behav 2000;67:325-330.

47. Heiberg IL, Wegener G, Rosenberg R. Reduction of cGMP and nitric oxide has antidepressant-like effects in the forced swimming test in rats. Behav Brain Res 2002;134:479-484.

48. Volke V, Wegener G, Bourin M, Vasar E. Antidepressant- and anxiolyticlike effects of selective neuronal NOS inhibitor 1-(2-trifluorome thylphenyl)-imidazole (TRIM) in mice. Behav Brain Res 2003;140:141147.

49. Wegener G, Volke V, Harvey BH, Rosenberg R. Local, but not systemic, administration of serotonergic antidepressants decreases hippocampal nitric oxide synthase activity. Brain Res 2003;959:128-134.

50. Ulak G, Mutlu O, Akar FY, Komşuoğlu FI, Tanyeri P, Erden BF. Neuronal NOS inhibitor 1-(2-trifluoromethylphenyl)-imidazole augment the effects of antidepressants acting via serotonergic system in the forced swimming test in rats. Pharmacol Biochem Behav 2008;90:563-568.

51. Campos AC, Piorino EM, Ferreira FR, Guimaraes FS. Increased nitric oxide-mediated neurotransmission in the medial prefrontal cortex is associated with the long lasting anxiogenic-like effect of predator exposure. Behav Brain Res 2013;1;256:391-397.

52. Rodwell VW. Metabolism of Proteins \& Amino Acids, Biosynthesis of the Nutritionally Nonessential Amino Acids. In: Murray RK, Bender DA, Botham KM, Kennelly PJ, Rodwell VW, Weil PA, Editors. Harper's Illustrated Biochemistry. 28th Ed. China: McGraw-Hill Companies, 2009. p. 478-479.

53. Cohen S, Nadler J. Proline-induced potentiation of glutamate transmission. Brain Res 1997;761:271-282.

54. Victor NJ, Wang A, Hakim A. Toxicity of L-proline toward rat hippocampal neurons. Brain Res 1988;456:168-172.

55. Delwing D, Bavaresco CS, Wannmacher CM, Wajner M, Dutra-Filho CS, Wyse AT. Proline induces oxidative stress in cerebral cortex of rats. Int J Dev Neurosci 2003;21:105-110.

56. Arikanoglu A, Akil E, Varol S, Yucel Y, Yuksel H, Cevik MU, et al. Relationship of cognitive performance with prolidase and oxidative stress in Alzheimer disease. Neurol Sci 2013;34:2117-2121.

57. Schroeter H, Boyd C, Spencer JP, Williams RJ, Cadenas E, Rice-Evans C. MAPK signaling in neurodegeneration: influences of flavonoids and of nitric oxide. Neurobiol Aging 2002;23:861-880.

58. Tsuruda T, Costello-Boerrigter LC, Burnett JC Jr. Matrix metalloproteinases: pathways of induction by bioactive molecules. Heart Fail Rev 2004;9:53-61.

59. Surazynski A, Liu Y, Miltyk W, Phang JM. Nitric oxide regulates prolidase activity by serine/threonine phosphorylation. J Cell Biochem 2005;96:1086-1094.

60. Nunoshiba T, deRojas-Walker T, Wishnok JS, Tannenbaum SR, Demple B. Activation by nitric oxide of an oxidative-stress response that defends Escherichia coli against activated macrophages. Proc Natl Acad Sci U S A 1993;90:9993-9997.

61. Endo F, Matsuda I, Ogata A, Tanaka S. Human erythrocyte prolidase and prolidase deficieny. Pediatr Res 1982;16:227-231.

62. Royce PM, Steinma B. Prolidase Deficiency. New York: Wiley-Liss; 1993.

63. Ceprnja M, Derek L, Unić A, Blazev M, Fistonić M, Kozarić-Kovacić $\mathrm{D}$, et al. Oxidative stress markers in patients with post-traumatic stress 
disorder. Coll Antropol 2011;35:1155-1160.

64. Tezcan E, Atmaca M, Kuloglu M, Ustundag B. Free radicals in patients with post-traumatic stress disorder. Eur Arch Psychiatry Clin Neurosci 2003;253:89-91.

65. Gergerlioglu HS, Savas HA, Bulbul F, Selek S, Uz E, Yumru M. Changes in nitric oxidelevel and superoxide dismutase activity during antimanic treatment. Prog Neuropsychopharmacol Biol Psychiatry 2007;31:697702.

66. Savas HA, Herken H, Yurekli M, Uz E, Tutkun H, Zoroğlu SS, et al. Possible role of nitricoxide and adrenomedullin in bipolar affective disorder. Neuropsychobiology 2002;45:57-61.

67. Bahceci B, Bagcioglu E, Kokacya MH, Dilek AR, Bahceci I, Selek S.
Prolidase activity and oxidative stress in patients with schizophrenia: A preliminary study. J Pak Med Assoc 2015;65:131-135.

68. Javitt DC. Glutamate and schizophrenia: phencyclidine, N-methyl-Daspartate receptors, and dopamine-glutamateinteractions. Int Rev Neurobiol 2007;78:69-108.

69. Krystal JH, D’Souza DC, Mathalon D, Perry E, Belger A, Hoffman R. NMDA receptor antagonist effects, cortical glutamatergic function, and schizophrenia: toward a paradigm shift in medication development. Psychopharmacology (Berl) 2003;169:215-233.

70. Yildiz A, Demirbag R, Yilmaz R, Gur M, Altiparmak IH, Akyol S, et al. The association of serum prolidase activity with the presence and severity of coronary arterydisease. Coron Artery Dis 2008;19:319-325. 